\title{
Algunas percepciones y conductas de los electores sobre la comunicación política y el marketing político*
}

\author{
Eliasib Naher Rivera Aya** \\ Liliana Catherine Suárez Báez ${ }^{* * *}$
}

Recibido:10 de enero de 2017 - Aprobado: 27 de marzo de 2017

\section{Resumen}

Este documento presenta los resultados de una investigación sobre marketing político orientado a identificar algunas conductas de los electores bogotanos frente a la oferta de propuestas de los candidatos en época electoral, así como a conocer algunas percepciones de los electores sobre la comunicación política que se lleva a cabo durante la época preelectoral.

Se considera el mercadeo político como una técnica que permite captar y conocer las necesidades, deseos y aspiraciones de una sociedad para luego ganar el poder y solucionar dichas necesidades. Asimismo, se considera la comunicación política como técnicas y procedimientos para el intercambio de discursos que llevan a cabo algunos actores políticos (políticos, comunicadores, periodistas) con el fin de influir o persuadir a otros actores políticos (los ciudadanos) de apoyar o no ciertas decisiones políticas, especialmente dentro de un régimen democrático. Los hallazgos del estudio se presentan en la sección de resultados del análisis cuantitativo y en la sección de conclusiones.

Palabras clave: marketing político; comunicación política; comportamiento electoral; electores

Artículo de investigación. Este documento surge de la investigación denominada "Caracterización de la mezcla de marketing político en las principales campañas a la alcaldía de Bogotá", proyecto financiado por la Universidad Jorge Tadeo Lozano y adscrito al Grupo de Investigación GICEAS - Grupo Interdisciplinario de Investigación en Ciencias Económicas, Administrativas y de Salud. DOI: http://dx.doi.org/10.15332/s0120-8454.2017.0091.07

** Magister en Administración, Universidad Nacional de Colombia. Profesor Asociado en el Departamento de Ingeniería de la Universidad Jorge Tadeo Lozano. Correo electrónico: eliasib.rivera@utadeo.edu.co. Código postal 110311. ORCID: http://orcid.org/0000-0002-5875-1080

*** Maestra en Mercadotecnia del Tecnológico de Monterrey, México, Profesor Asociado en la Escuela de Administración Contaduría y Mercadeo de la Universidad de Bogotá Jorge Tadeo Lozano. Correo electrónico: liliana.suarez@utadeo. edu.co. Código postal 110311. ORCID: http://orcid.org/0000-0001-8183-1815 


\title{
Some perceptions and behaviors of voters about political communication and political marketing*
}

\author{
Eliasib Naher Rivera Aya** \\ Liliana Catherine Suárez Báez ${ }^{* * *}$
}

\section{Abstract}

This paper presents the results of a research on political marketing aimed at identifying some of the behaviors of Bogotá's voters in relation to the offer of candidates' proposals in the electoral period, as well as to know some perceptions of voters about the political communication that takes place during the pre-election period.

Political marketing is considered as a technique that allows to capture and to know the needs, desires and aspirations of a society to later gain the power and to solve those needs. Likewise, political communication is considered as techniques and procedures for the exchange of speeches carried out by some political authors (politicians, communicators, journalists) in order to influence or persuade other political actors (citizens) to support certain decision policies, especially within a democratic regime.

The study findings are presented in the results section of the quantitative analysis an in the conclusions section.

Keywords: political marketing; political communication, electoral behavior; voters

Research article. This document results from the research called "Characterization of the mixture of political marketing in the main campaigns for the mayor of Bogota office", project financed by the University Jorge Tadeo Lozano and appointed to the Research Group GICEAS - Interdisciplinary Group of Research in Economic, Administrative and Health Sciences. DOI: http://dx.doi.org/10.15332/s0120-8454.2017.0091.07

** Master's Degree in Administration, National University of Colombia. Associate Professor in the Engineering Department of the University Jorge Tadeo Lozano. Email: eliasib.rivera@utadeo.edu.co. Postal code 110311. ORCID: http://orcid. org/0000-0002-5875-1080

*** Master's Degree in Marketing from Monterrey Tecnology Institute, Mexico, Associate Professor at the School of Administration, Accounting and Marketing at the University of Bogotá Jorge Tadeo Lozano. E-mail: liliana.suarez@ utadeo.edu.co. Postal code 110311. ORCID: http://orcid.org/0000-0001-8183-1815 


\title{
Quelques perceptions et comportements des électeurs sur la communication politique et le marketing politique*
}

\author{
Eliasib Naher Rivera Aya** \\ Liliana Catherine Suárez Báez ${ }^{* * *}$
}

\section{Résumé}

Cet article présente les résultats d'une enquête sur le markting politique visant à identifier certains comportements des électeurs de Bogota face à l'offre des propositions des candidats en période électorale, et à connaître quelques perceptions des électeurs au sujet de la communication politique qui se déroule pendant la période préélectorale.

On considére le marketing politique comme une technique qui permet de capturer et de comprendre les besoins, les désirs et les aspirations d'une société, pour ensuite gagner le pouvoir et résoudre ces besoins. On considére également la communication politique comme les techniques et les procédures pour l'échange de discours soutenus par les acteurs politiques (politiciens, journalistes, médias) afin d'influencer ou de convaincre d'autres acteurs politiques (citoyens) de soutenir ou non certaines décisions politiques, en particulier dans un régime démocratique. Les résultats de l'étude sont présentés dans la section de résultats de l'analyse quantitative et dans la section des conclusions.

Mots clés: marketing politique; communication politique; comportement électoral; électeurs

Article de recherche. Ce document provient de la recherche intitulée « Caractérisation du mélange de marketing politique dans les principales campagnes pour la mairie de Bogota », projet financé par l'Université Jorge Tadeo Lozano et adscrit au groupe de recherche - Groupe interdisciplinaire de recherche en Sciences Économiques, Administratives et de la Santé.

** Magister en Administration, Université Nationale de Colombie. Professeur du Département d'Ingénierie de l' Université Jorge Tadeo Lozano. Email: eliasib.rivera@utadeo.edu.co. Code postal 110311. ORCID: http://orcid. org/0000-0002-5875-1080

*** Professeur en Marketing del Tecnológico de Monterrey, Mexique, Professeur à l'École d'Administration, Contabilité et Marketing de I'Université de Bogota Jorge Tadeo Lozano. Email: liliana.suarez@utadeo.edu.co. Code postal 110311. ORCID: http://orcid.org/0000-0001-8183-1815 


\section{Introducción}

El comportamiento electoral ha sido un tema objeto de múltiples investigaciones y planteamientos teóricos desde diferentes disciplinas. El saber qué mueve o motiva el comportamiento de los votantes en un contexto electoral es motivo de estudio y análisis por parte de diversos investigadores. Este documento presenta algunas percepciones de los electores frente a acciones de marketing político, así como algunas conductas relacionadas con la etapa preelectoral frente a la comunicación política.

En la primera parte del documento se presentan algunos referentes teóricos tales como marketing político, comunicación política y comportamiento electoral, así como algunos estudios previos sobre el tema y la metodología utilizada en el estudio. En la segunda parte se presentan los resultados relacionados con percepciones sobre marketing político, campañas políticas y su grado de transparencia o engaño, grado de saturación de las campañas políticas, actividades de comunicación preferidas por los encuestados, razones para elegir una propuesta política y acciones preferidas por los encuestados para informarse en época preelectoral. La tercera parte presenta las conclusiones del estudio.

\section{Algunos referentes teóricos: marketing político, comunicación política y comportamiento electoral}

\section{Marketing político}

En general, el mercadeo se define como "las actividades que las personas efectúan al obtener, consumir y disponer de productos y servicios" (Blackwell, Miniard, y Engel, 2002). En otras palabras, cómo y por qué compran las personas. El mercadeo es un área de estudio que busca satisfacer las necesidades de consumidores y usuarios a través de propuestas de valor (bienes y servicios). Sin embargo, derivaciones posteriores han aplicado el mercadeo a problemáticas sociales, a empresas no lucrativas y al mercadeo político, en cuyo caso el mercadeo trabaja alrededor de ideas, valores, ideologías, programas de gobierno, etc., por lo que maneja intangibles diferentes a los servicios. Así que la misión del marketing dentro del mercadeo político sería el conocimiento e identificación de las necesidades más apremiantes de una sociedad, la comunicación de la ideología, los programas y posturas políticas de los partidos, buscando ganar elecciones para finalmente mejorar la calidad de vida de los electores. Por lo tanto, el mercadeo político es la aplicación de los principios del marketing en la política y en las elecciones. El marketing político busca fortalecer un partido político a través de influir en los ciudadanos por medio de información alrededor de planes de gobierno y posturas ideológicas que resuelvan sus problemáticas más apremiantes, presentando soluciones convincentes y reales. De manera 
complementaria, el marketing electoral -que se realiza generalmente en los dos o tres meses previos a la elección- se concentra en ganar las elecciones y se centra en el posicionamiento del candidato y su programa de gobierno, así como en sintonizarlo con las necesidades de los electores para conseguir su voto y ganar las elecciones para desarrollar un programa de gobierno enfocado en solucionar las problemáticas de los electores o ciudadanos.

\section{Comunicación política}

“La comunicación política es un concepto relativamente joven; el vocablo se empezó a utilizar en la década de los cincuenta, pero sus antecedentes se manifiestan desde que el hombre comenzó a vivir en grupo y se presentaron relaciones de poder en la convivencia" (Reyes, O'Quínn, Morales, y Rodríguez, 2010, p. 86). En concordancia con esto, "el marketing político, así como la comunicación política, hacen su aparición en Estados Unidos, como una iniciativa global organizada, en la campaña presidencial de Eisenhower, en 1952" (Maarek, 2009, p. 21). Al respecto, Beccassino (2003) indica que, "en los años cincuenta, el general Eisenhower fue el primer presidente norteamericano que encomendó la tarea de la comunicación a especialistas, a una agencia de publicidad, al tiempo que se asesoró de un actor de cine para que lo preparara para manejar su relación personal con las cámaras de televisión. El resultado: Eisenhower demolió al demócrata Adlai Stevenson" (p. 12).

Sin embargo, para Maarek (2009), "los cuatro debates televisados de la campaña electoral entre Jhon F. Kennedy y Richard Nixon, en 1960, se consideran como el nacimiento de la comunicación política moderna. Dado que Nixon perdió la presidencia por 100.000 votos, una cantidad ínfima en Estados Unidos, a partir de ese momento los debates televisados, junto con los anuncios publicitarios por televisión, adquirieron un valor determinante en las elecciones democráticas" (p. 37).

Como se dijo antes, aunque el vocablo "comunicación política" se empezó a utilizar en la década de los cincuenta, Crespo y Moreno (2015) recuerdan que, en Europa, entre 1921 y 1930, la radio se popularizó a gran velocidad y constituyó el primer medio de comunicación a través del cual desarrollar anuncios políticos, realizar discursos e intervenciones o dirigir alocuciones políticas. Presentan como ejemplo a Joseph Goebbels, ministro de propaganda de Hitler, quien desarrolló un plan gubernamental para producir receptores de radio de bajo costo para facilitar su adquisición por cada hogar alemán (estos aparatos de radio solo permitían captar las emisiones de las emisoras nazis). Indican además que "en esa época circularon interpretaciones -que no tenían nivel de teorías, sino solo suposiciones- relacionadas con "la aguja hipodérmica", que presuponía un poder ilimitado a la comunicación política a través de los medios de comunicación masivos de la época: la radio y el cine, al creer que se podía influir sobre un gran número de personas de manera directa y uniforme "inyectándoles" mensajes específicamente diseñados para generar una 
determinada respuesta. Esta visión fue predominante desde la década de 1920 hasta la década de 1940" (Crespo y Moreno, 2015, p. 78). Luego vinieron los estudios de la comunicación de masas de los años cuarenta, "que comenzaron a introducir herramientas metodológicas más elaboradas y complejas a fin de medir el poder de influencia de los medios sobre sus audiencias, [...] y es en la década de los sesenta, con la aparición de los debates político-electorales en televisión, que aparecen los primeros trabajos sobre la comunicación política" (Reyes, et al., p. 89).

Por otra parte, desde el punto de vista conceptual, para explicar el término "comunicación política", diversos autores, entre ellos Canel (2006) y Cortés (2009), consideran necesario explicar primero por separado el significado de "comunicación" y el de "política". Para este último, "la comunicación es un proceso simbólico mediante el cual se produce, mantiene, repara y transforma la realidad, en la medida en que busca influir y persuadir, es decir, el intento que hace el orador de llevar a los demás a tener su mismo punto de vista" (Cortés, 2009, p. 11). Considera, además, que "la política es el arte de gobernar a los pueblos, o la intención de hacerlo dictando leyes y órdenes con autoridad general, cumpliéndolas y haciéndolas cumplir para remediar las necesidades de los ciudadanos y promover el bien público" (Cortés, 2009, p. 12). Destaca que "la comunicación política se concibe con un fin específico, el cual no es meramente informar, sino convencer, persuadir o incluso disuadir" (Cortés, 2009, p. 15). Propone asimismo una definición operacional de comunicación política: "es una forma de persuasión basada en la utilización de cualquier recurso que implique el intercambio de signos con el fin de influir políticamente en el escenario de la sociedad moderna. Ello implica, ciertamente, una forma de búsqueda del poder y dominación en la sociedad contemporánea" (Cortés, 2009, p. 23).

Por otra parte, para Canel (2006) la política se entiende como "la actividad por la que se adoptan y aplican las decisiones en y para la comunidad" (p. 18). Reconoce la existencia de una estrecha relación entre la política y la comunicación, puesto que "esta última incide sustancialmente en la actividad de adopción y aplicación de decisiones en y para la comunidad" (p. 18). Respecto de la evolución de la definición de comunicación política, Canel (2006) rescata la que a su juicio es la primera definición de comunicación política, que apareció en el libro Political Behaviour, publicado en 1956 por Eulau, Eldersveld y Janowitz:

Uno de los tres procesos (junto con el liderazgo político y las estructuras de grupo) de intervención por medio del cual se movilizan y transmiten las influencias políticas entre unas instituciones gubernamentales formales y el ciudadano -votante-. La comunicación política es entendida aquí como un proceso mediador, en el sentido de que es por ella por la que se hace posible la relación entre las instituciones gubernamentales y los electores". (Canel, 2006, p. 20)

Canel (2006) considera que "comunicación política es la actividad de determinadas personas e instituciones (políticos, comunicadores, periodistas y 
ciudadanos), en la que, como resultado de la interacción, se produce un intercambio de mensajes con los que se articula la toma de decisiones políticas, así como la aplicación de estas en la comunidad" (p. 27), en tanto que para Sibaja (2012), la comunicación política puede ser entendida como "el proceso de gestión de la visibilidad del ejercicio del poder de quienes lo ejercen, lo aspiran, lo respaldan o lo adversan. En dicho proceso se incluyen las estrategias de construcción, promoción, intercambio y recepción de discursos, a menudo contradictorios, con contenidos estratégicos, simbólicos y contextuales. Este intercambio de discursos se da en el espacio público, bajo reglas conocidas y previamente establecidas, es altamente mediatizado. Estos discursos pueden asumir diversidad de formas, pero siempre tienen intenciones persuasivas y legitimadoras" (p. 40).

En resumen, se entenderá aquí por comunicación política a las técnicas y procedimientos para el intercambio de discursos que llevan a cabo algunos actores políticos (políticos, comunicadores, periodistas) con el fin de convencer a otros actores políticos (los ciudadanos) de apoyar o no ciertas decisiones políticas, especialmente dentro de un régimen democrático.

Respecto a las áreas de actividad o de estudio de la comunicación política, existe un alto grado de similitud entre lo que plantean Canel (2006) y Ochoa (2000). Este último plantea las siguientes áreas: opinión pública (estudiar actitudes y opiniones de los ciudadanos aplicando sondeos, entrevistas y análisis de medios), análisis de contenido (identificar tendencias en los medios de comunicación), propaganda política (usar recursos y medios para difundir determinada ideología), conducta político-social (hacer estudios para conocer e identificar las conductas de la sociedad en cuanto a la política, liderazgo y grupos de poder (estudiar a los líderes y grupos de poder en la sociedad) y efectos de la comunicación política (estudios para identificar qué efectos provoca la comunicación).

Por su parte, tanto Canel (2006) como Vásquez (2012) consideran que las áreas de estudio de la comunicación política son:

a. "Estudios que se centran en el análisis del mensaje de la comunicación política, que, amparados en disciplinas como la retórica o la lingüística, incluyen en análisis de los contenidos de los mensajes, los temas, las metáforas, el lenguaje político, los discursos y la simbología política" (Canel, 2006, p. 28; Vásquez, 2012).

b. "Estudios que se centran en los procesos políticos que acompañan la Comunicación Política. Aquí se encuentran los estudios sobre la gestión de imágenes de realidades políticas como el régimen político, la Presidencia, el Parlamento, etc." (Canel, 2006, p. 28; Vásquez, 2012).

c. "Estudios que se centran en las acciones de la comunicación, es decir, en las distintas formas que puede adoptar el mensaje de la comunicación política, [...] entre las que están las siguientes: la publicidad política; los mensajes 
informativos de los eventos político-comunicativos; los mensajes de ficción (como los mensajes del humor político o los talk shows); las posibilidades de los nuevos medios para realizar actividades comunicativas diversas" (Canel, 2006, p. 29; Vásquez, 2012).

d. "Estudios que se centran en la mediación del mensaje realizado por los medios de comunicación, [...] que incluye: la relación entre políticos y periodistas; la sociología de redacciones de los medios de comunicación; el fenómeno de la personalización de la política en los medios de comunicación; la cobertura que los medios de comunicación dan a las instituciones políticas: ejecutivo (presidencia y gobiernos), legislativo (parlamentos) y judicial (tribunales); la creación de climas de opinión política por parte de los medios de comunicación, a través de los enfoques de las noticias, del editorialismo y del humor político; las crisis políticas generadas por los medios de comunicación; la cobertura de los asuntos internacionales, que incluye el papel de loa opinión pública en la diplomacia, el flujo internacional de información, la cobertura del tercer mundo, y las cuestiones relacionadas con la globalización" (Canel, 2006, p. 29; Vásquez, 2012).

e. "Los estudios que se centran en los efectos del mensaje de la comunicación política en todos los niveles. [...] Estos incluyen: la búsqueda y procesamiento de la información política por parte del ciudadano; la influencia de los medios de comunicación en los ciudadanos: procesos de formación de la opinión pública (influencias en el conocimiento, juicio y comportamientos de los ciudadanos); la influencia de la comunicación interpersonal en los juicios y comportamientos políticos de los ciudadanos; la contribución de los medios de comunicación a la socialización política y, de manera particular, a la educación cívica; los cambios de actitudes: información y actitudes políticas, información política y creencias políticas, información política y participación ciudadana, motivaciones del público para el uso de los medios de comunicación; y por último, una nueva área de trabajo es el estudio del impacto de los nuevos medios: el incremento de canales de comunicación, la contribución al compromiso cívico, las posibilidades de interacción, etc." (Canel, 2006, p. 30; Vásquez, 2012).

Este estudio corresponde a esta última clasificación (efectos del mensaje de la comunicación política), dado que se centró en conocer percepciones de los encuestados sobre marketing político y sobre comunicación política.

\section{Comportamiento electoral}

Para Valdez y Huerta (2011), “el saber qué mueve o motiva el comportamiento de los votantes en una coyuntura o contexto electoral es un interrogante presente [...] en las indagaciones de los estudiosos de la ciencia política, [...] así como de la sociología, la antropología, la psicología y la mercadotecnia política; pero sobre todo de los políticos y candidatos que durante los procesos electorales 
tratan de incidir en la conducta y comportamiento de los ciudadanos" (p. 2). Asimismo, Cárdenas (2013) plantea que "el comportamiento electoral ha sido históricamente un tema objeto de múltiples investigaciones y planteamientos teóricos de diversas disciplinas. Desde la psicología social, pasando por la economía y la ciencia política, se han trazado muchas hipótesis y aproximaciones teóricas que buscan explicar el comportamiento de los seres humanos frente a la decisión de votar por un candidato, un partido o una propuesta en la contienda electoral" (p. 3).

Por su parte, Guzmán y Ramírez (2015) plantean que

La tradición del estudio del comportamiento electoral indica que existe un conjunto de factore que contribuye a la estabilidad del mismo; entre aquellos más estudiados son la ideología, la clase social y la religión, los que se distinguen por su capacidad de amarrar el voto. En el caso de las democracias con baja capacidad de amarre del voto por alguna de estas vías u otras, los efectos se relacionan, entre otros, con la escasa institucionalización de los sistemas de partidos. (p. 183)

Sin embargo, aunque

Los estudios electorales tratan de aislar los condicionamientos para identificar los factores que inciden en el acto de votar, en el estudio del comportamiento electoral las respuestas al interrogante acerca de qué factores son los que predominan al momento de tomar la decisión del voto continúan sin respuestas que logren el consenso académico. [...] A pesar de esto, en el marco de cualquier análisis de comportamiento electoral se siguen mencionando las teorías sociológica, psicológica y racional para estudiar al elector. (Guzmán y Ramírez, 2015, p. 170)

La teoría sociológica para abordar el estudio electoral destaca los rasgos sociales, las características sociodemográficas y la influencia de grupos como factores que explican la decisión del voto. La teoría psicológica propone la revisión e influencia de la identificación partidista como elemento explicativo del voto. La teoría racional, más conocida como la teoría de la elección racional, considera la evaluación que los ciudadanos hacen o pueden hacer de la gestión del partido de gobierno, de las características y habilidades de los candidatos o de la posición de estos en temas importantes, de manera que luego el ciudadano establezca una relación costo/beneficio que se convierte en un posible determinante del voto.

Al respecto, Valdez y huerta (2011) referencian que varias décadas atrás surgieron

Algunas teorías para identificar los factores de mayor influencia en la decisión del votante: [...] la teoría conductista, la teoría racional y la teoría cultural del voto. [...] El conductismo sostiene que a todo 
estímulo le sigue una respuesta, similar a la relación que existe entre causa y efecto, siendo la respuesta el resultado de la interacción entre el individuo que recibe el estímulo y el medio ambiente. [...] Esta teoría se aplicó y evolucionó en el campo de la comunicación política hacia lo que se conoce como la teoría de los efectos. Por su parte, la teoría racional considera al elector como un ser racional [...] porque evalúa las diferentes opciones políticas que se le presenta y decide racionalmente, tomando en cuenta sus prioridades e intereses. [...] A su vez, la teoría cultural enfatiza aspectos históricos, inerciales y tradicionales (por ejemplo, la tradición familiar), así como de hábito de sufragio, la cultura política o la pertenencia a un determinado grupo social, cofradía o comunidad como elementos que predisponen, de cierta manera, el voto. (Valdez y Huerta, 2011, p. 4)

El comportamiento electoral está ligado al estudio del electorado. Sobre la tipología del electorado, hay distintas formas de clasificarlo, como, por ejemplo, si vive en una zona rural o una zona urbana; a partir de información demográfica (sexo, edad, nivel de estudios, ocupación). Pero la tipología más común es la forma habitual como ha votado el elector, clasificándolo en cuatro categorías: el voto duro (electores que muestran gran identidad, lealtad e identificación con determinado partido, por el que siempre votarán, independientemente de los candidatos que postulen o la circunstancia política que se viva en el momento); el voto blando (el elector tiene un grado de simpatía con el partido pero evalúa la coyuntura del momento, el tipo de candidatos postulados y la oferta electoral); el voto opositor (los electores manifiestan su oposición o rechazo hacia el partido y los candidatos que postula), y el elector indeciso (aquel poco involucrado en la política y poco informado de los asuntos públicos, que no manifiesta identidad, simpatía o lealtad con ninguna fuerza partidista) (Valdez y Huerta, 2011).

Como complemento al tema de este apartado, seis grandes corrientes teóricas del comportamiento electoral se muestran a continuación (ver Tabla 1). 
Tabla 1. Corrientes teóricas del comportamiento electoral

\begin{tabular}{|c|c|}
\hline Corriente & Resumen \\
\hline \multirow[b]{2}{*}{$\begin{array}{l}\text { Corriente histórico- } \\
\text { sociológica }\end{array}$} & $\begin{array}{l}\text { Modelo de la Universidad de Michigan. Dos fuerzas afectan los } \\
\text { resultados de la decisión electoral: una a largo plazo (la distribución } \\
\text { de lealtades partidistas en el electorado) y otra a corto plazo (los } \\
\text { candidatos y sus propuestas). Por lo tanto, la decisión del elector } \\
\text { está mediada por las variables partido, propuestas y candidato, } \\
\text { y la importancia de estas variables varía conforme al tiempo, al } \\
\text { lugar y al contexto político en que se desarrolle la elección. En } \\
\text { este modelo interactúan variables históricas (partidos políticos, } \\
\text { identificación partidaria) y variables contingentes (candidatos, } \\
\text { contexto) (Cárdenas, 2013). }\end{array}$ \\
\hline & $\begin{array}{l}\text { Teoría del voto de clase. Circunstancias como "que un ciudadano } \\
\text { sea de clase obrera o burgués; católico, judío o protestante; de } \\
\text { origen autóctono o inmigrante; joven o viejo; que viva en una } \\
\text { ciudad o en un pequeño pueblo, no son hechos neutros. Son cir- } \\
\text { cunstancias que sitúan al ciudadano en un lugar determinado de } \\
\text { la estructura social del país, influyendo en cómo mira el mundo, la } \\
\text { política y las elecciones, modificando el voto de los ciudadanos" } \\
\text { (Anduiza y Bosch, 2004; citados por Cárdenas, 2013, p. 4). Los } \\
\text { individuos, dentro de su clase, interactúan con otras personas y } \\
\text { reciben información dentro de ese contexto social que influye en su } \\
\text { comportamiento. El elector, consciente de su interés de clase, actúa } \\
\text { consecuentemente. Esta teoría descansa en algunos preceptos } \\
\text { históricos y teóricos que no tienen actualmente tanto peso en los } \\
\text { análisis, pero que no pueden descartarse del todo (Cárdenas, 2013). }\end{array}$ \\
\hline \multirow{2}{*}{$\begin{array}{l}\text { Corriente } \\
\text { económico-racional }\end{array}$} & $\begin{array}{l}\text { Teoría de la democracia liberal. Parte del supuesto de que el } \\
\text { hombre es primariamente una criatura racional y así son todas sus } \\
\text { decisiones. El voto es el resultado de un cálculo racional basado } \\
\text { en el acceso a una información suficiente y confiable de los pro- } \\
\text { blemas y necesidades de su entorno, de los partidos, candidatos y } \\
\text { propuestas, y de un análisis y evaluación racional de sus principios } \\
\text { propios y su ideología. Supone que el ciudadano ejerce su derecho } \\
\text { a decidir libremente en condiciones de total acceso a la información } \\
\text { y es producto de un cálculo racional de lo que es más conveniente } \\
\text { para él a la luz de sus convicciones políticas (Cárdenas, 2013). }\end{array}$ \\
\hline & $\begin{array}{l}\text { Teoría de la elección racional. Basada en el concepto de "utilidad", } \\
\text { sugiere que el hombre es racional cuando acude a las urnas y } \\
\text { tiene un pensamiento individualista en sus decisiones políticas. El } \\
\text { individuo analiza todas las opciones que tiene ante sí respecto a } \\
\text { las consecuencias que cada una tendría y escoge la que le propor- } \\
\text { cione mayor utilidad, según sea la más adecuada para conseguir } \\
\text { sus fines (Cárdenas, 2013). Se persiguen los medios que son } \\
\text { eficientes y efectivos para lograr la consecución de objetivos dada } \\
\text { una estructura de creencias y valores (Remes, 2001). }\end{array}$ \\
\hline
\end{tabular}




Corriente de la
comunicación
política
"Asocia el
comportamiento
electoral a la
influencia que
pueden tener todas
las estructuras
y dinámicas de
la comunicación
al interior del
contexto en el cual
se desenvuelven
los individuos"
(Cárdenas, 2013).

Teoría de la comunicación en múltiples pasos. La decisión electoral no es fruto de una decisión meramente individual y auto razonada. El elector se interrelaciona con otras personas bajo diversas estructuras en donde está expuesto al intercambio de información, opiniones y percepciones que pueden incidir en su decisión. "Existen cuatro fenómenos o estructuras sociales en donde se interrelacionan las personas y en donde se desarrollan las actitudes y se estimulan los comportamientos: los líderes de opinión, los grupos, las redes de comunicación y la familia. Estos pueden servir como puntos de referencia para la toma de decisiones electorales. Esta teoría abarca la existencia de redes de comunicación en donde circula la información en diferentes niveles y en las cuales los individuos tienen un sustento importante a la hora de emitir sus juicios en la decisión final" (Cárdenas, 2013, p. 5).

También considera conceptos para ver la influencia de los medios de comunicación en las decisiones de los electores (conocidos como "los efectos de los medios"): priming, framing, agenda setting, mostrando el carácter influyente y activo de los medios de comunicación en torno a la información que ponen a circular en la sociedad (Cárdenas, 2013).

\section{Corriente de la psicología política}

"Se centra en el trasfondo psicológico de los juicios ciudadanos, es decir, en la valoración que éstos hacen de la actividad política, sus participantes, y la importancia que ésta tiene para las personas y el conjunto del orden social" (Cárdenas, 2013).

Perspectiva politológica
Teoría del voto retrospectivo o de castigo. "En esta teoría el voto está determinado por la evaluación de la actividad gubernamental. En especial, las condiciones económicas desempeñan un papel importante en conformar las decisiones electorales. Si el elector se encuentra financieramente en buen estado y con unas buenas condiciones de vida, optará por premiar al titular del cargo público. También evalúa la seguridad (en lo amplio de su expresión), la confianza y todos los temas relacionados con el liderazgo político y la capacidad de un gobernante de suplir las necesidades materiales y emocionales de las personas" (Cárdenas, 2013, p. 5).

Teoría expresiva del voto. Según esta teoría, "el acto de votar es una actividad pública con significación social. El elector se ve relejado en los valores, propuestas y candidatos que participan y vota por el que represente sus valores propios. El elector está en la búsqueda de símbolos políticos que le generen recompensas y simpatías expresivas. [...] El elector busca unos valores políticos semejantes que le den certeza de que su elección va a tener un peso relevante en el futuro de su comunidad" (Cárdenas, 2013, p. 5).

"El análisis se centra en cómo las transformaciones institucionales moldean y modifican el comportamiento electoral a través de cambios en el sistema electoral que den una mayor apertura, o por el contrario, busquen corregir desequilibrios en aspectos como la representatividad y el exceso de movimientos y partidos políticos" (Cárdenas, 2014, p. 6). Sobre los sistemas de partidos y sus diferentes tipologías, dos autores los conceptualizan así:

Andrés Malamud (2003) propone dos principales tipologías de los sistemas de partidos: las de Maurice Duverger (sistemas unipartidistas, bipartidistas y multipartidistas) y Giovanni Sartori (unipartidismo de partido único, unipartidismo de partido hegemónico, unipartidismo de partido predominante, bipartidismo, multipartidismo limitado, multipartidismo extremo y multipartidismo atomizado). 


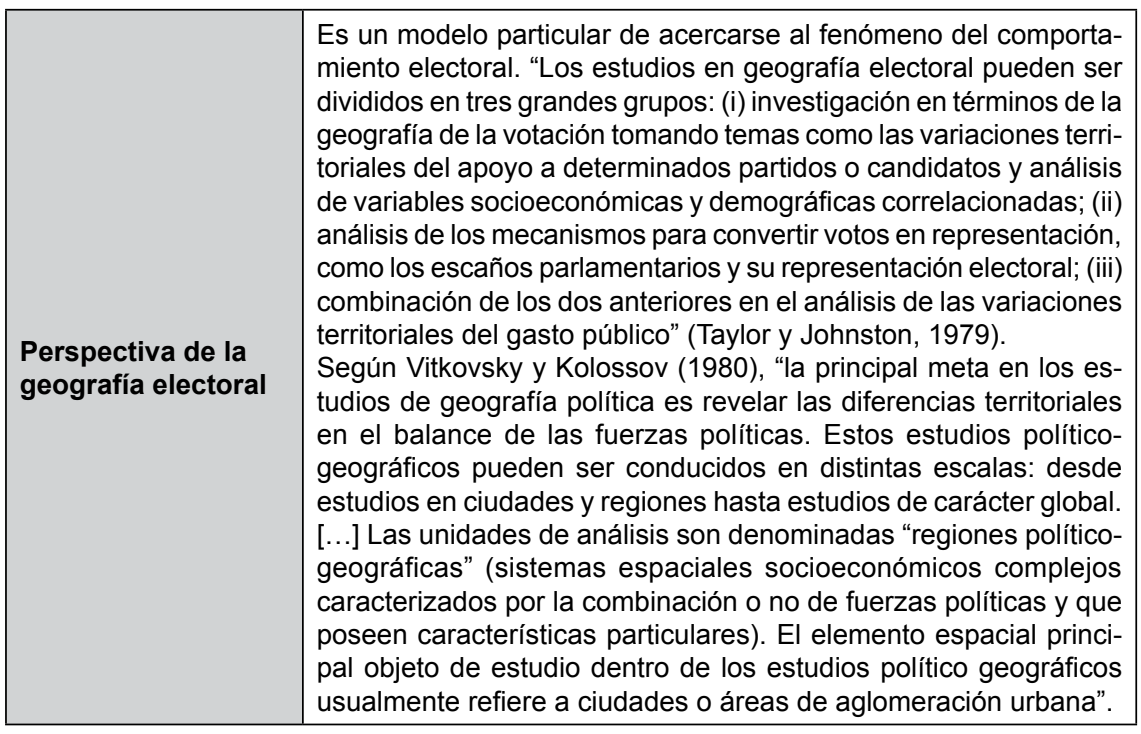

Fuente: elaboración propia a partir de Cárdenas (2013).

Este estudio se clasifica dentro de la corriente de la comunicación política, dado que busca identificar algunas percepciones de los electores en época electoral a partir de las dinámicas de comunicación que se presentan durante los días previos a una elección.

\section{Antecedentes}

En Colombia se han adelantado estudios previos relacionados con marketing político y con comunicación política. Entre ellos están:

La MOE (2011) realizó un estudio sobre la percepción electoral de los votantes colombianos, en el cual, a través de una encuesta, se indaga sobre factores de decisión del voto (medios de comunicación, encuestas, partido político, conocimiento sobre financiación de campañas), el comportamiento y opinión electoral sobre grupos específicos (mujeres, afrodescendientes, indígenas, discapacitados), acciones que atentan contra la libertad del voto (compra y venta del voto, presión para votar o no), confianza en entidades públicas (Registraduría, Contraloría, Defensoría, Asamblea Departamental o Concejo de la ciudad), nivel de importancia de ciertos temas (corrupción, derechos humanos, empleo, calidad de la política, seguridad urbana, concentración del poder, bienestar social, parapolítica, infraestructura, cultura, movilidad), opciones para solucionar la lucha armada contra las FARC (vía militar, diálogo, zona de distención), agenda legislativa electoral (reelección inmediata de alcaldes y gobernadores, eliminación del voto preferente, reducir la edad para votar), agenda legislativa nacional (legalización del consumo de marihuana, eliminación de la tutela para acceder a servicios de 
salud fuera del POS -Plan Obligatorio de Salud-, el Estado debe devolver las tierras a los desplazados, distribución de las regalías por todo el territorio nacional de manera proporcional). Algunos resultados de este estudio relacionados con los medios de comunicación muestran que, "entre nueve factores que influyen a la hora de escoger un candidato, y entre las alternativas "Muy influyente", "Nada influyente", $\mathrm{y}^{\prime \prime} \mathrm{NS} / \mathrm{NR}^{\prime}$, los cuatro con mayor porcentaje de "Muy influyente" son: trayectoria académica y laboral del candidato (86\%), temas y propuestas de los candidatos (87.6\%), información que divulguen los medios de comunicación (69.9\%) y partido del candidato (61.8\%)" (MOE, 2011, p. 17). Los demás factores tuvieron un porcentaje menor al 50\% en la opción "Muy influyente".

Rodríguez-Raga y Seligson (2011) presentaron un estudio sobre la cultura política de la democracia en Colombia en el que abordan temas como actitudes democráticas y antidemocráticas; democracia estable y confianza en las instituciones; seguridad ciudadana, corrupción y conflicto armado, y participación política y comportamiento electoral. En este último tema está incluido lo relacionado con factores explicativos de la participación política, citando los siguientes: confianza interpersonal (confianza del encuestado en las personas que lo rodean); participación en organizaciones de la sociedad civil (organización religiosa; asociación de padres de familia; junta de mejoras para la comunidad; asociación de profesionales/comerciantes/productores/organizaciones campesinas). Sin embargo, en este estudio no se abordaron indagaciones relacionadas con la comunicación política.

España y Rivera (2012) realizaron un estudio sobre los universitarios y la democracia en Bogotá orientado a identificar las expectativas, percepciones y costumbres políticas de los estudiantes universitarios en la ciudad y sus motivaciones para ejercer o no su derecho al voto. En lo referente a la comunicación política, algunos resultados presentados son:

El 74\% de los estudiantes universitarios encuestados dice buscar información en época electoral para conocer a los candidatos y sus propuestas o programas políticos. [...] En términos generales, las formas más usadas por ellos para buscar información son la internet, la televisión y las charlas con los candidatos. [...] Los medios que más se descartan para dicha búsqueda son las sedes de los partidos, las revistas, los volantes y los amigos. (España y Rivera, 2012, p. 36)

Sobre la influencia de los medios de comunicación en la elección de un candidato, "el $64 \%$ de los estudiantes universitarios encuestados considera que los medios de comunicación son totalmente influyentes o influyentes en la elección de un candidato. El 17\% los considera poco o nada influyentes" (España y Rivera, 2012 , p. 37). "En cuanto al grado de importancia para votar por un candidato, los tres factores considerados como muy importantes, en su orden, son: transparencia, plan de gobierno y mejoras generales en la calidad de vida. Le siguen credibilidad, postura ideológica, y el factor que menos fue considerado como importante fue el partido político" (España y Rivera, 2012, p. 40). 
Guzmán y Ramírez (2015) realizaron un estudio para identificar el perfil del elector colombiano en las elecciones presidenciales de 2002, 2006 y 2010. Se preguntó ¿en qué factores cada partido debería centrar su atención? Es decir, ¿cuáles son las semejanzas y diferencias en términos de sofisticación política, orientación político-partidista y características sociodemográficas entre los ciudadanos que prefieren electoralmente al Partido Liberal, el Polo o la U? [partidos políticos en Colombia]. Los indicadores de la dimensión "sofisticación política" son: consumo de medios de comunicación, interés por la política, principal fuente de información política y nivel educativo más alto alcanzado. Los indicadores de la dimensión "orientación político-partidista" son: simpatía o identificación con un partido y autoubicación ideológica en el espacio político de izquierda-derecha. Los indicadores de la dimensión "características sociodemográficas" son: sexo, edad, estrato socioeconómico, zona de residencia, ocupación, condición salarial, religión, y estado civil. Encontraron que, en los aspectos relacionados con la sofisticación política, el nivel educativo resulta ser un aspecto significativo para los tres momentos electorales (2002, 2006 y 2010) al mostrar un nivel alto de asociación con la preferencia electoral. Algo similar ocurre con el interés en la política y con el consumo de medios de comunicación, siendo este último aspecto diferenciable entre los electores del Polo, que consumen con mayor frecuencia la prensa, frente a los de la U y del Partido Liberal, en los que prevalece la televisión y a su vez presentan un bajo o nulo consumo de prensa. Sobre la orientación político-partidista, encontraron que

El posicionamiento en el continuo ideológico izquierda-derecha, junto con la identificación con un partido, son elementos a los que un elector puede recurrir para la toma de su decisión electoral. [...] Sobre las características socio-demográficas, no encontraron variables que se asocien significativamente a la preferencia electoral para las tres elecciones. Tanto el estrato social como la zona de residencia, el género y la religión se observó una relación entre éstas y el voto a un determinado partido, el coeficiente de contingencia es muy bajo, por lo que no permite una conclusión satisfactoria. [...] En lo referente a la evaluación de la gestión, encontraron que, para el año 2010, la valoración de buena gestión se asocia al voto uribista, mientras que la valoración regular o mala se asocia significativamente con el Partido Liberal y el Polo. [...] [Concluyen que] la sofisticación política y la valoración de la gestión son las dimensiones que destacan por las diferencias que se identifican entre los ciudadanos que prefieren votar por los partidos Liberal, la U y el Polo. (Guzmán y Ramírez, 2015, p. 185)

Cárdenas (2013) propone un modelo de análisis multidimensional para la caracterización del comportamiento electoral a partir de integrar distintas variables de orden histórico y coyuntural, individuales y colectivas, legales y extralegales, formales e informales, teóricas y pragmáticas. Aunque identifica seis tipos de corrientes teóricas del comportamiento electoral (histórico-sociológica, económico-racional, corriente de la comunicación política, corriente de 
la psicología política, perspectiva politológica y perspectiva de la geografía electoral), enmarcó su estudio dentro de dos corrientes: la politología -que permite conjugar elementos de la ciencia política como el sistema de partidos, los partidos políticos y niveles electorales- y la corriente de la geografía electoral -que ofrece el elemento del territorio, que tiene un lugar preponderante en el análisis que hace dicho autor-.

Propone un modelo multidimensional de análisis del comportamiento electoral que comprende al menos siete dimensiones:

1. Historia: construcción del estado-nación y las instituciones políticopartidistas y su evolución diacrónica.

2. Coyuntura: agenda temática, los actores, intereses y escenarios del momento electoral.

3. Individuos: construcción de liderazgos y el territorio psicopolítico de la acción individual y colectiva.

4. Cultura política: hábitos y comportamientos colectivamente sostenidos y perpetuados frente a la relación sociedad-estado-política.

5. Legislación: marco jurídico e institucional para la competencia político-ideológica y la lucha por el poder.

6. Estructura social: formación ideológica, social y económica. Grupos e ideas predominantes.

7. Clivajes y "anclajes": conflictos latentes al interior de las sociedades que generan distintos marcos valorativos e ideológicos que guían la acción colectiva e individual en el ámbito electoral.

8. Geografía electoral: presencia de elementos geográficos diferenciales, humor político, migraciones, presencia/abandono estatal. (Cárdenas, 2013, p. 8)

Cárdenas (2013) afirma que "el estudio del comportamiento electoral no debe hacerse de manera desintegrada, dejando de lado factores que pueden incidir en el análisis, sino que hay que considerar fenómenos tanto históricos como coyunturales, políticos y no políticos, colectivos e individuales y a aspectos puntuales específicos de la cultura política de cada sociedad" (p. 18).

Respecto de la politología, analiza el hecho de la dicotomía de pensamiento que ha predominado hasta nuestros días, representada en el Partido Liberal y el Partido Conservador, reflejando dos visiones muy distintas en aspectos como la educación la religión, la economía y los alcances de los derechos civiles y políticos, entre otros. 
Ese sistema político bipartidista cerraba el acceso a otros sectores de la sociedad a la competencia por los cargos de poder político en el país, hasta la Constitución Política de 1991 que, junto con el inicio de la elección popular de alcaldes y gobernadores, reorganiza institucionalmente el sistema haciendo más fácil y accesible la participación política de otros grupos y sectores de la sociedad, especialmente en el ámbito de las elecciones locales. Igualmente, las apariciones de políticos carismáticos van evidenciando el paso de votación de los ciudadanos más por partidos que por candidatos. (Cárdenas, 2013, p. 12)

Y en cuanto a la geografía como factor de importancia para estudiar el comportamiento electoral colombiano, Cárdenas (2013) considera que la geografía accidentada y diversa se ajusta a la fragmentación social que también caracteriza al país. Destaca que los procesos electorales se han venido transformando gracias al proceso de expansión de los medios de comunicación, pero que los partidos han venido cediendo su papel protagónico a la importancia progresiva de otros factores asociados a la imagen y la exposición mediática de la política: más que propuestas e ideas, lo que prevalece son los "issues" o temas de la agenda construidos por los medios y a la exaltación de la imagen de los candidatos frente a esos temas por encima de las posiciones ideológicas y de partidos. Considera que el conflicto armado también es un factor de importancia en el comportamiento electoral de los colombianos, en parte por las posiciones opuestas sobre cómo abordar el problema de los grupos armados (confrontación militar o negociación), así como por la influencia que grupos armados ilegales ejercen en ciertas zonas geográficas del país sobre los votantes.

El descenso de la imagen favorable de las instituciones y el desprestigio de los partidos políticos llevó al surgimiento de nuevos movimientos y liderazgos que aprovechan la acogida del discurso antipolítico, como Andrés Pastrana y Álvaro Uribe, que llegaron a la presidencia mediante movimientos ciudadanos de recolección de firmas y con discursos distantes de los partidos tradicionales. (Cárdenas, 2013, p. 16)

\section{Objetivo principal}

Identificar algunas percepciones de los electores frente a acciones de marketing político, así como algunas conductas relacionadas con la etapa preelectoral respecto de la comunicación política.

\section{Metodología y recolección de la información}

Se realizó un estudio descriptivo transversal, con enfoque cuantitativo. Se utilizó un instrumento estructurado y se aplicaron 324 encuestas a ciudadanos de 
Bogotá de todas las edades y estratos, mayores de edad. Se realizó un muestreo no probabilístico por conveniencia. Además, se hizo una validación telefónica.

\section{Perfil de la muestra}

La muestra está compuesta por el 56\% ( $n=181)$ de hombres y el $44 \%(n=142)$ de mujeres. El 1.9\% (n=6) son de estrato 1, el 15,3\% $(n=47)$ de estrato 2, el 38\% $(n=117)$ de estrato 3, el $34.1 \%(n=105)$ de estrato 4 , el $7.1 \%(n=22)$ de estrato 5 , y el 3.6\% (n=11) de estrato 6. El 47.3\% (n=149) de la muestra, tienen entre 18 y 24 años, el 10.2\% (n=32) tiene entre 25 y 30 años, el 13.3\% (n=42) tiene entre 31 y 40 años, el 16.5\% (n=52) tiene entre 41 y 50 años y el 12.7\% (n=40) restante tiene más de 50 años.

\section{Resultados del análisis cuantitativo}

A partir de las 324 encuestas aplicadas a la muestra elegida, se presentan a continuación los resultados tabulados y analizados.

Gráfico 1. Razón principal para elegir una propuesta política

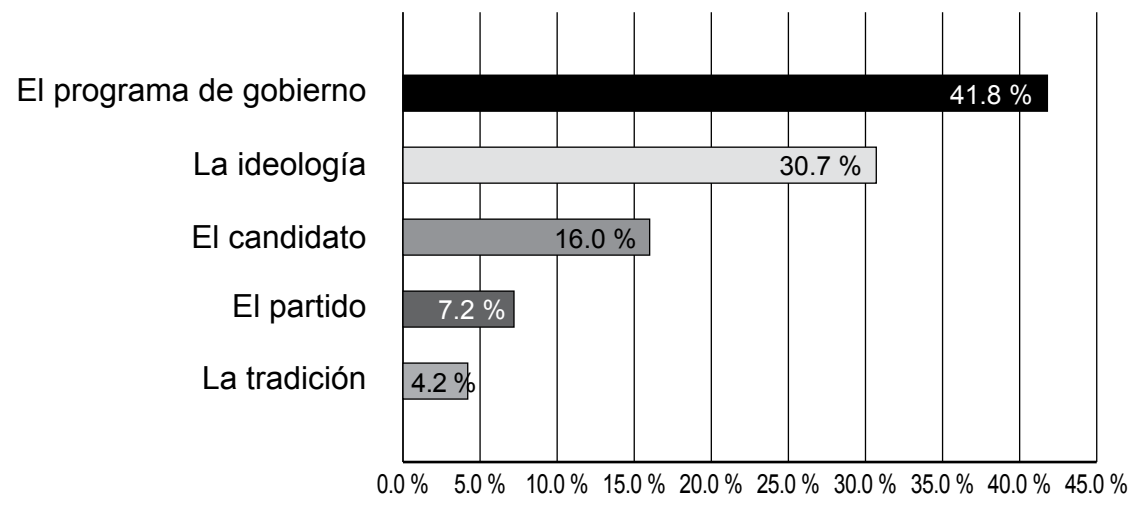

Fuente: cálculos de los autores con base en la encuesta aplicada.

En la pregunta sobre la razón principal que influye en la decisión de votar por una propuesta política se buscaba jerarquizar los posibles influenciadores que puede tener una persona a la hora de votar y se encontró que el influenciador principal para el voto es el programa de gobierno con un $41.8 \%(n=128)$, seguido de un 30.7\% (n=94) por la ideología, el 16\% $(n=49)$ por el candidato, el $7.2 \%$ $(n=22)$ por el partido y el restante $4.2 \%(n=13)$ por la tradición. 
Gráfico 2. Cómo se informa para votar

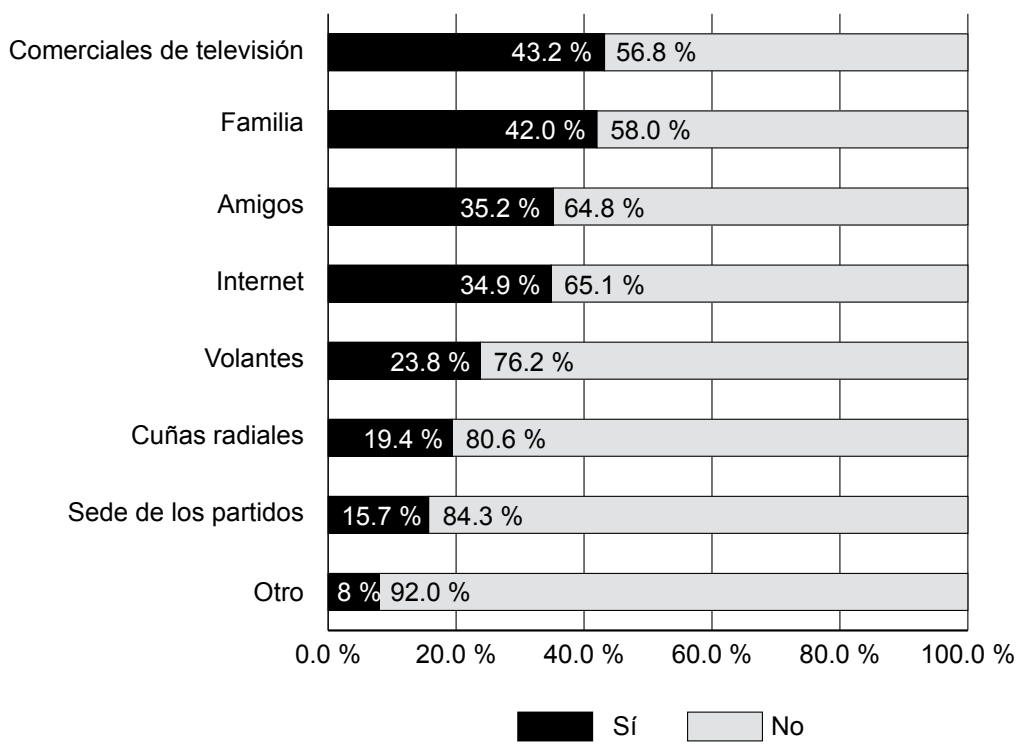

Fuente: cálculos de los autores con base en la encuesta aplicada.

La pregunta sobre cómo se informa para votar indagaba sobre los medios por los cuales los encuestados se informaban en época electoral. El medio por el que más se informan es por comerciales de televisión $43.2 \%(n=140)$, seguidos de un $42 \%$ (n=136) que se informa con su familia, el 35.2\% ( $n=114)$ se informa con amigos, el 34.9\% ( $n=113)$ por Internet, el 23.8\% ( $n=77)$ por medio de volantes, el 19.4\% (n=63) se informa con cuñas radiales, el $15.7 \%(n=51)$ en la sede de los partidos políticos y un $8 \%(n=26)$ dice que se informa por otros medios.

Gráfico 3. Grado en que la publicidad influye en su decisión de por quién votar

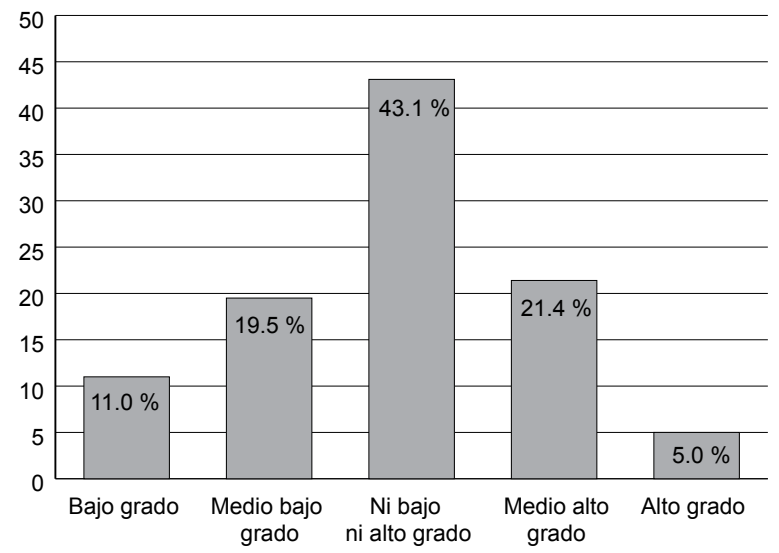

Fuente: cálculos de los autores con base en la encuesta aplicada. 
Al indagar sobre el grado en que las acciones de publicidad influyen en su decisión al votar, el $43.1 \%(n=137)$ de los encuestados muestra indiferencia ante la afirmación. El 29.1\% asegura que las acciones de publicidad generan una influencia en mediano y alto grado (medio alto grado $21.4 \%(n=68)$ y alto grado $5 \%(n=16))$. El 30.5\% dice que las acciones publicitarias los influencian en mediano y bajo grado (medio bajo grado $19.5 \%(n=62)$ y bajo grado $11 \%(n=35)$ ).

Gráfico 4. Acciones que realiza en época preelectoral

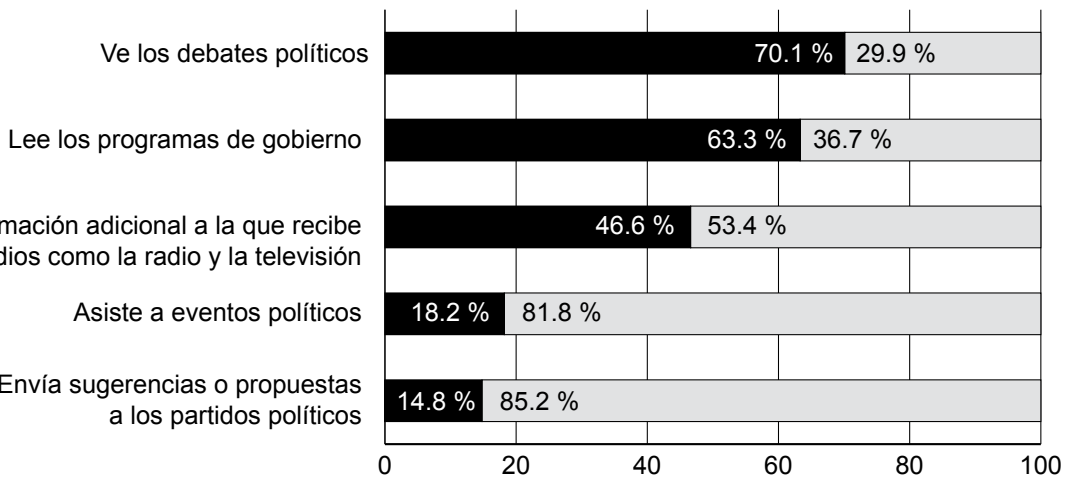

Fuente: cálculos de los autores, con base en la encuesta aplicada.

Con la pregunta sobre las acciones que el encuestado acostumbra realizar en época preelectoral se buscaba identificar las conductas que tienen los encuestados en esta época. Se observó que la principal acción de los encuestados es ver los debates políticos con un $70.1 \%$ ( $n=227)$, seguido de leer los programas de gobierno con un $63.3 \%$ ( $\mathrm{n}=205)$, buscan información adicional a la que reciben en medios como la radio y la televisión en un $46.6 \%(n=151)$, el 18.2\% (n=59) asiste a eventos políticos y el $14.8 \%(\mathrm{n}=48)$ envía sugerencias o propuestas a los partidos políticos.

Gráfico 5. Existencia o no de manipulación a través de las campañas políticas

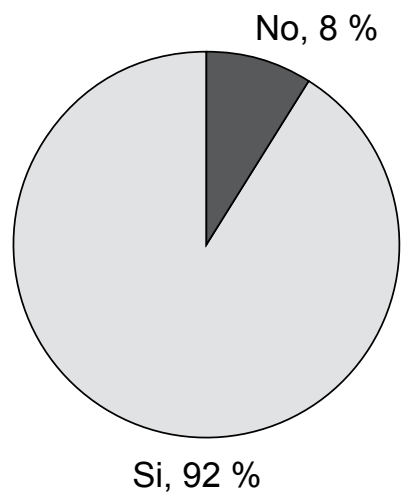

Fuente: cálculos de los autores con base en la encuesta aplicada. 
Al preguntarle al encuestado si cree que existe manipulación a través de las campañas políticas, el 92\% (n=297) de los encuestados considera que sí existe manipulación a través de las campañas políticas, mientras el $8 \%(n=27)$ restante considera que no.

Gráfico 6. Grado de transparencia de los debates, las propuestas políticas y los programas de gobierno

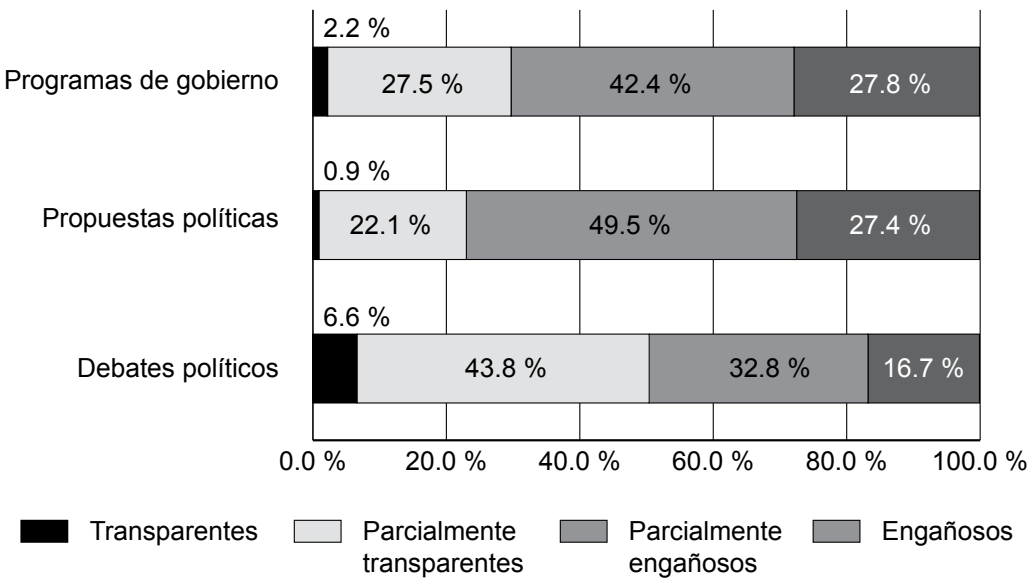

Fuente: cálculos de los autores con base en la encuesta aplicada.

Al indagar sobre el grado en que los debates políticos, los programas de gobierno y las propuestas políticas engañan a la gente o son transparentes, se encontró una mayor confianza en los debates políticos, dado que fue considerado como el más transparente (6.6\%), así como el que tenía mayor porcentaje de "parcialmente transparente" (43.8\%). Asimismo, fueron los debates políticos los que tuvieron menor porcentaje en el rango de "engañosos" (16.7\%). Los resultados para cada una de las tres alternativas indagadas fueron:

- Programas de gobierno: el 70.2\% de los encuestados considera que los programas de gobierno son parcialmente engañosos y engañosos $(42,4 \%(n=134)$ parcialmente engañosos y $27.8 \%$ ( $n=88$ ) engañosos); un $29.7 \%$ considera que los programas de gobierno son parcialmente transparentes y transparentes $(27.5 \%(n=87)$ parcialmente transparentes y un $2.2 \%(n=7)$ transparentes).

- Propuestas políticas: el 76.9\% de los encuestados considera que las propuestas políticas son parcialmente engañosas y engañosas $(49.5 \%(n=157)$ parcialmente engañosos y $27.4 \%$ ( $n=87$ ) engañosos); un $23 \%$ considera que los programas de gobierno son parcialmente transparentes y transparentes $(22.1 \%(n=70)$ parcialmente transparentes y un $0.9 \%(n=3)$ transparentes).

- Debates políticos: el 50.4\% de los encuestados considera que los debates políticos son parcialmente transparentes y transparentes $(43,8 \%(n=139)$ parcialmente transparentes y $6.6 \%(\mathrm{n}=21)$ transparentes $)$; un $49.5 \%$ considera 
que los programas de gobierno son parcialmente engañosos y engañosos (32.8\% ( $n=104)$ parcialmente engañosos y un $16.7 \%(n=53)$ engañosos).

Gráfico 7. ¿Se aplica el concepto de mercadeo político en Colombia?

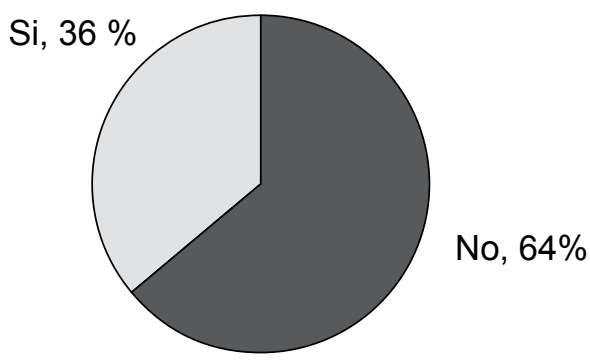

Fuente: cálculos de los autores con base en la encuesta aplicada.

Se le presentó a los encuestados una definición de mercadeo político para conocer su consideraban que ese concepto se aplica o no en Colombia, indicando que "el mercadeo político lo entendemos como una técnica que permite captar y conocer las necesidades, deseos y aspiraciones de una sociedad para luego ganar el poder y solucionar dichas necesidades". El 64\% (n=206) de los encuestados considera que esta definición de mercadeo político no se aplica en Colombia, mientras que el 36\% (n=118) considera que sí.

Gráfico 8. ¿El mercadeo político es una herramienta útil para la democracia?

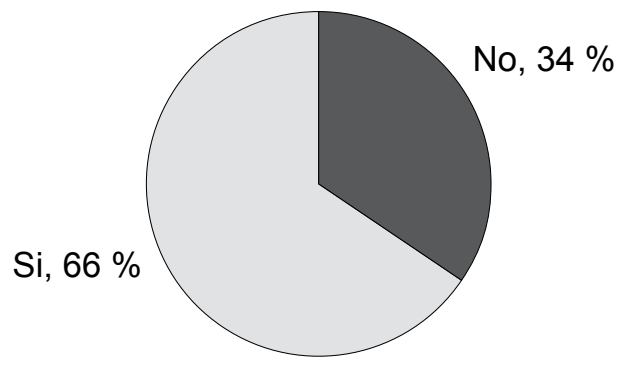

Fuente: cálculos de los autores con base en la encuesta aplicada.

El 66\% ( $\mathrm{n}=215)$ de los encuestados piensa que el mercadeo político es una herramienta útil para la democracia, mientras que el restante $34 \%(n=109)$ considera que no lo es. 
Gráfico 9. Medios más confiables de los partidos políticos para dar a conocer sus propuestas

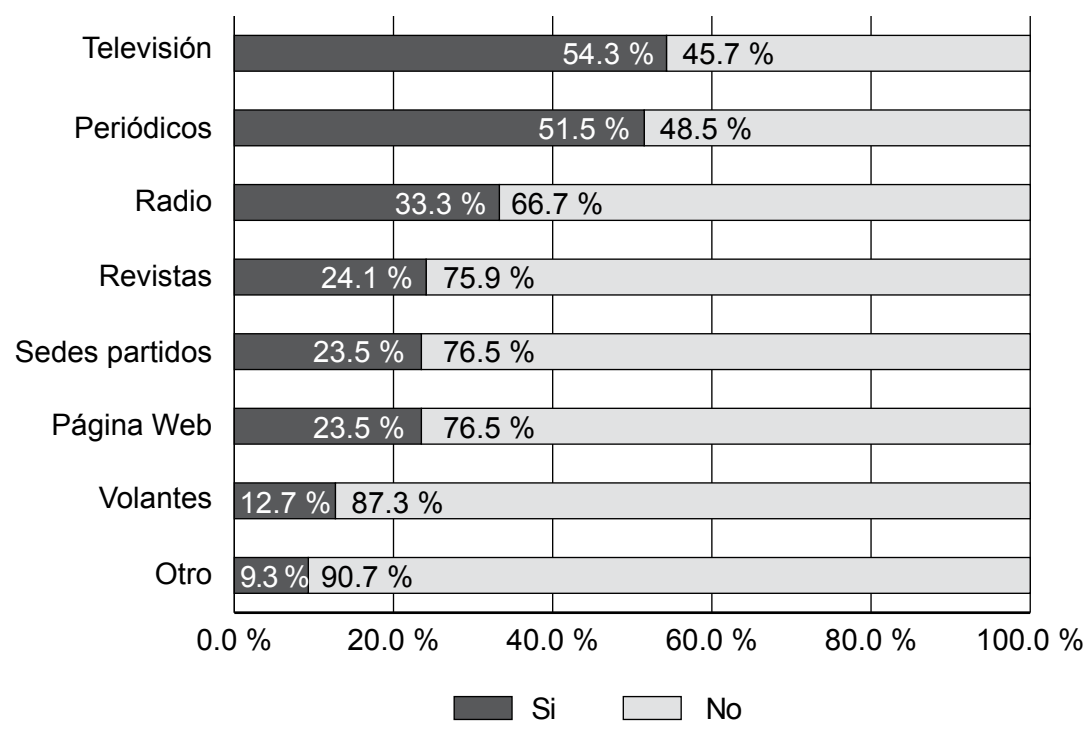

Fuente: cálculos de los autores con base en la encuesta aplicada.

A la pregunta sobre qué medios le parecen más confiables en época electoral con los que los partidos dan a conocer sus propuestas, para los encuestados el medio más confiable en época electoral es la televisión $54.3 \%(n=176)$, seguido de los periódicos con un $51.5 \%(n=167)$, la radio con un $33.3 \%(n=108)$, las revistas con un $24.1 \%(n=78)$, las sedes de los partidos con un $23.5 \%(n=76)$, las páginas web en un $23.5 \%(n=76)$, los volantes con un $12.7 \%(n 41=)$ y el $9.3 \%(n=30)$ piensa que otros medios son más confiables.

Gráfico 10. ¿Le cree usted a la publicidad en época electoral?

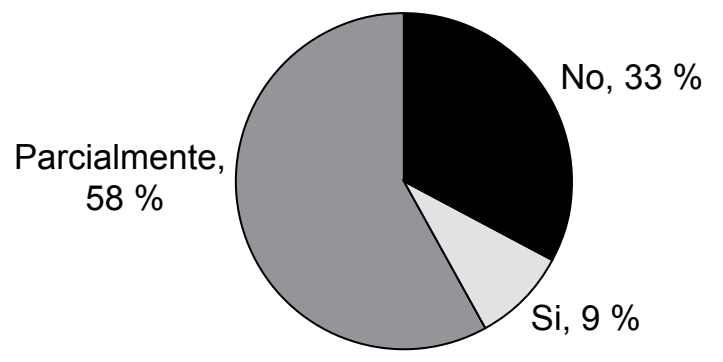

Fuente: cálculos de los autores con base en la encuesta aplicada.

Al preguntarle a los encuestados si le cree a la publicidad en época electoral, el $58 \%(\mathrm{n}=187)$ de los encuestados le cree parcialmente a la publicidad en época electoral, el 9\% (n=29) le cree y el 33\% (n=104) no le cree. 
Gráfico 11. Grado percibido de saturación de propaganda política en época electoral

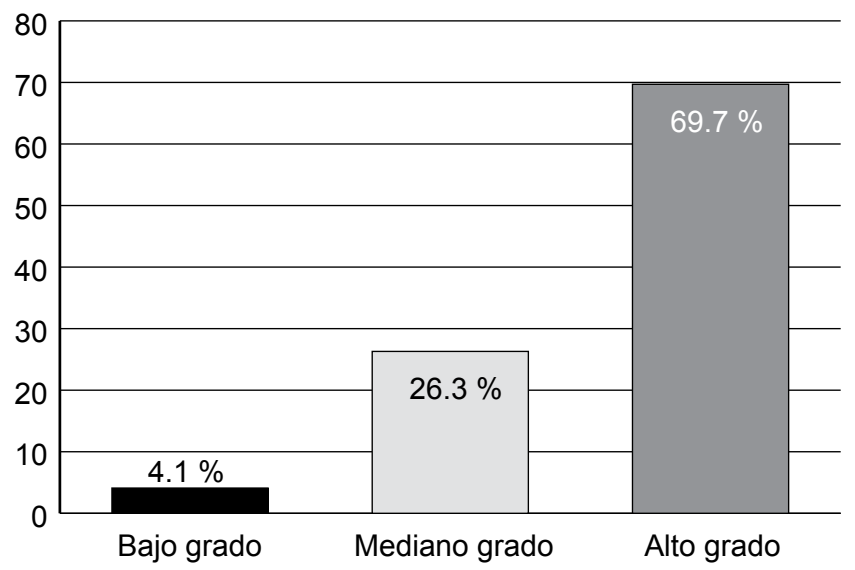

Fuente: cálculos de los autores con base en la encuesta aplicada.

Al preguntarle a los encuestados sobre el grado percibido de saturación de propaganda política en época electoral, el 69.7\% (n=223) de los encuestados percibe un alto grado de saturación en la propaganda política, seguido de un $26.3 \%(n=84)$ que percibe un mediano grado de saturación, y el $4.1 \%(n=13)$ restante percibe un grado bajo de saturación de propaganda política.

Gráfico 12. Actividades de comunicación preferidas por los encuestados en época electoral

Debates por televisión

Conferencias en universidades

Reuniones en los barrios

Comerciales en televisión

Cuñas de radio

Discursos en eventos

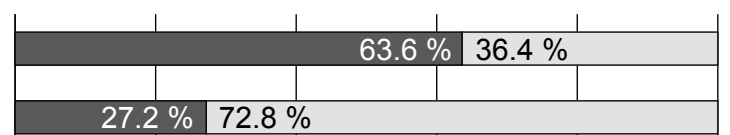

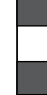

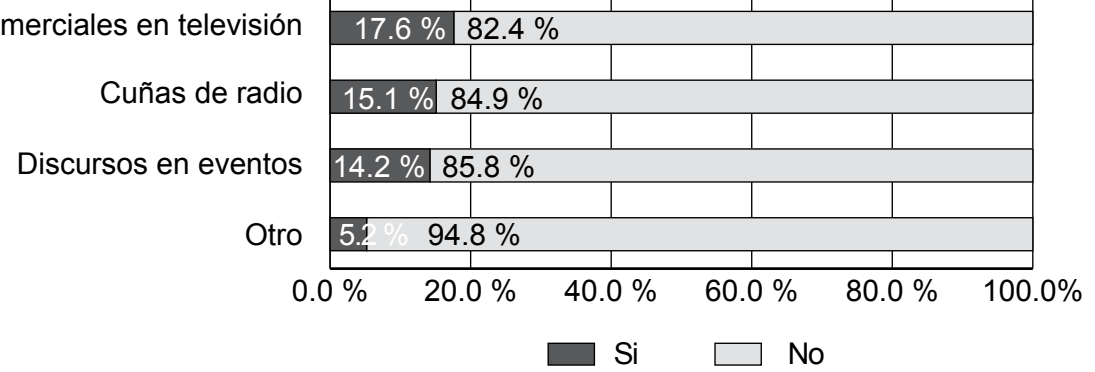

Fuente: cálculos de los autores con base en la encuesta aplicada.

En la pregunta sobre “¿cuáles son las actividades de comunicación que realizan los candidatos en época electoral que más le gustan?”, se buscó jerarquizar las actividades de comunicación que hacen los candidatos en época electoral. 
Se encontró que a la mayoría de los encuestados, 63.6\% ( $\mathrm{n}=206)$, le gusta los debates por televisión, seguidos del $27.2 \%(n=88)$ que dicen que les gustan las conferencias en universidades, el $20.4 \%(\mathrm{n}=66)$ dice que le gustan las reuniones en los barrios, el 17.6\% $(n=57)$ los comerciales de televisión, el 15.1\% $(n=49)$ las cuñas radiales, el $14.2 \%(n=46)$ los discursos en eventos y el restante $5.2 \%(n=17)$ le gustan otras actividades.

\section{Análisis de tablas de contingencia}

Las tablas de contingencia permiten contrastar algunas variables relevantes de la investigación con algunas características de los encuestados. Por ejemplo, permite conocer la relación entre el estrato y la razón principal del voto, la edad y la capacidad de la publicidad para influir en la decisión de voto de los encuestados, el nivel de disposición para ver los debates políticos según el estrato al que pertenece el encuestado, entre otras relaciones.

Gráfico 13. Diferenciación entre el estrato y la razón principal del voto

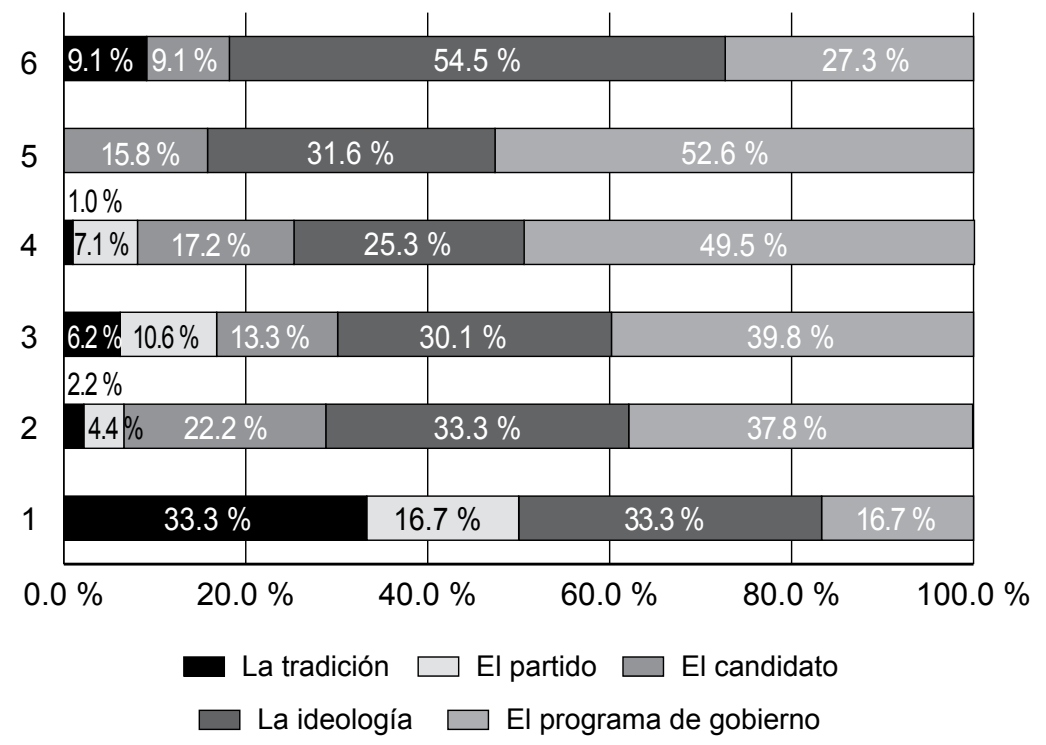

Fuente: cálculos de los autores con base en la encuesta aplicada.

Se buscó establecer una comparación entre las razones principales de voto por cada uno de los estratos de los ciudadanos en Bogotá. Se observa una relación directa entre el estrato y el programa de gobierno como razón principal del voto (a mayor estrato, mayor porcentaje del programa de gobierno como razón principal del voto), excepto en el estrato 6, que disminuye esta relación. La ideología resulta ser un factor para votar relativamente estable en casi todos los estratos, oscilando entre el $25.3 \%$ y el $33.3 \%$, excepto en el estrato 6 que es 
del 54.5\%. Se observa también que el candidato como razón principal del voto decrece en la medida en que aumenta el estrato, excepto en el estrato 1, que no considera al candidato como razón principal del voto.

También se observa que, en conjunto, la ideología y el programa de gobierno son razones que van creciendo en la misma medida en que crece el estrato, mientras que la tradición, el partido y el candidato son razones que decrecen a medida que aumenta el estrato. Precisamente las dos razones principales para votar en casi todos los estratos son la ideología y el programa de gobierno, excepto en el estrato 1, en el cual se reparten por igual los porcentajes conjuntos de ideología y programa de gobierno con los porcentajes de tradición y partido.

Se puede concluir que existe una tendencia marcada sobre la influencia de voto en los estratos que votan principalmente por programa político e ideología, sin embargo, se observa una ruptura en el estrato 6, que vota de manera muy definida por la ideología, y el estrato 1, que da una alta importancia a la tradición en el momento de votar.

De manera más específica por estratos, se encuentra que:

- Estrato 1: las dos razones principales de voto en este estrato son la tradición (33.3\%)y la ideología (33.3\%), seguido del partido y el programa de gobierno en proporciones iguales, del $16.7 \%$. Según los resultados de la encuesta, en este estrato el candidato no resulta ser una razón principal para votar.

- Estrato 2: este estrato vota motivado principalmente por programa de gobierno $37.8 \%$ e ideología $33.3 \%$, seguido del candidato $22.2 \%$, el partido $4.4 \%$ y la tradición $2,2 \%$.

- Estrato 3: la razón principal de voto de este estrato es principalmente por programa de gobierno (39.8\%) e ideología (30.1\%), seguidos del candidato $(13.3 \%)$, el partido (10.6\%) y la tradición $(6.2 \%)$.

- Estrato 4: el estrato 4 vota con mayor influencia del programa de gobierno $(49.5 \%)$, seguido de la ideología $(25.3 \%)$, el candidato $(17.2 \%)$, el partido $(7.1 \%)$ y la tradición $(1 \%)$.

- Estrato 5: la mayoría de personas del estrato 5 tiene el programa de gobierno como razón principal para votar (52.6\%), seguido de la ideología con un $31.6 \%$, y el candidato con un $15.8 \%$. En este estrato nadie vota por el partido ni por la tradición.

- Estrato 6: la razón principal para votar en el estrato 6 es en su mayoría la ideología (54.5\%), seguida del $27.3 \%$ que vota por el programa de gobierno, y por último en igualdad de proporción están el candidato y la tradición, cada uno con el 9.1\%. 
Gráfico 14. Diferenciación entre la edad y el grado de influencia de las acciones publicitarias

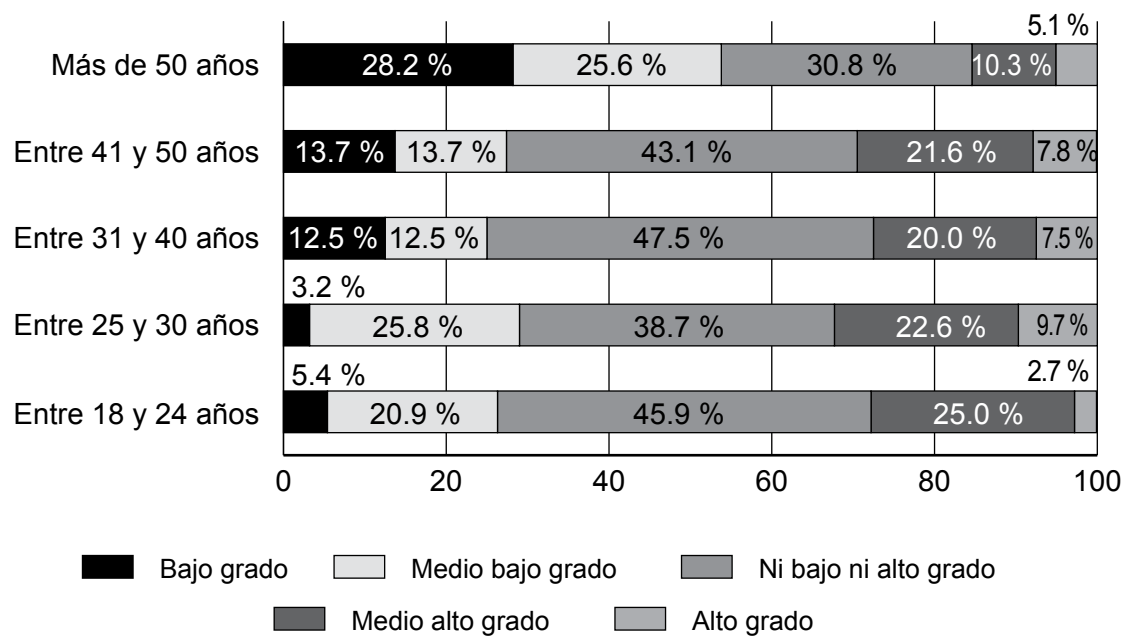

Fuente: cálculos de los autores con base en la encuesta aplicada.

Se buscó establecer una comparación entre el grado de influencia de las acciones publicitarias en el voto por cada uno de los rangos de edad medidos en la encuesta. En general puede observarse que, a mayor rango de edad del encuestado, menor grado de influencia de las acciones publicitarias. Lo anterior puede inferirse al observar las tendencias del comportamiento del bloque de bajo grado de influencia, así como el bloque de medio alto grado.

De manera más detallada por rangos de edad, se encuentra que:

- Entre 18 y 24 años: de las 148 personas que tienen entre 18 y 24 años, se observa que el $5.4 \%(n=8)$ dice que las acciones de publicidad tienen un bajo grado de influencia sobre su decisión de voto, un $20.9 \%(n=31)$ dice que el grado de influencia es medio bajo, un $45.9 \%(n=68)$ dice que el grado de influencia no es ni bajo ni alto, el 25\% (n=37) dice que el grado de influencia es medio alto y el $2.7 \%(n=4)$ dice que el grado de influencia de las acciones publicitarias en su decisión de voto es alto.

- Entre 25 y 30 años: de las 31 personas que están en este rango de edad, el $29 \%(n=9)$ dice que el grado de influencia de las acciones de publicidad en la decisión de voto es bajo y medio bajo (bajo $3.2 \%(n=1)$ y medio bajo $25.8 \%(n=8))$; el 38.7\% ( $n=12)$ dice que el grado de influencia no es ni alto ni bajo, el $32.3 \%(n=10)$ dicen que el grado en que las acciones de publicidad influyen en su decisión de voto es medio alto y alto (medio alto $22.6 \%(n=7)$ $\mathrm{y}$ alto $9.7 \%(\mathrm{n}=3))$.

- Entre 31 y 40 años: de las 40 personas que tienen entre 31 y 40 años, se observa que el $12.5 \%(n=5)$ dice que las acciones de publicidad tienen un 
bajo grado de influencia sobre su decisión de voto, un $12.5 \%(n=5)$ dice que el grado de influencia es medio bajo, un $47.5 \%(n=19)$ dice que el grado de influencia no es ni bajo ni alto, el $20 \%(n=8)$ dice que el grado de influencia es medio alto y el $7.5 \%(n=3)$ dice que el grado de influencia de las acciones publicitarias en su decisión de voto es alto.

- Entre 41 y 50 años: de las 51 personas que están en este rango de edad, el $27.4 \%(n=9)$ dice que el grado de influencia de las acciones de publicidad en la decisión de voto es bajo y medio bajo (bajo $13.7 \%$ (n=7) y medio bajo $13.7 \%(n=7))$; el $43.1 \%(n=22)$ dice que el grado de influencia no es ni alto ni bajo, el 29.4\% ( $\mathrm{n}=15)$ dicen que el grado en que las acciones de publicidad influyen en su decisión de voto es medio alto y alto (medio alto $21.6 \%(n=11)$ y alto $7.8 \%(n=4))$.

- Más de 50 años: de las 39 personas que tienen más de 50 años, se observa que el $28.2 \%$ (n=11) dice que las acciones de publicidad tienen un bajo grado de influencia sobre su decisión de voto, un 25.6\% (n=10) dice que el grado de influencia es medio bajo, un $30.8 \%(n=12)$ dice que el grado de influencia no es ni bajo ni alto, el 10.3\% (n=4) dice que el grado de influencia es medio alto y el $5.1 \%(n=2)$ dice que el grado de influencia de las acciones publicitarias en su decisión de voto es alto.

Se puede concluir que las acciones publicitarias tienen mayor influencia sobre el público adulto-joven, se observa un cambio de comportamiento después de los 50 años, pues en este segmento las personas dicen que las acciones publicitarias los influencian en bajo grado.

Gráfico 15. Diferenciación entre el estrato y la conducta de ver debates políticos en época electoral

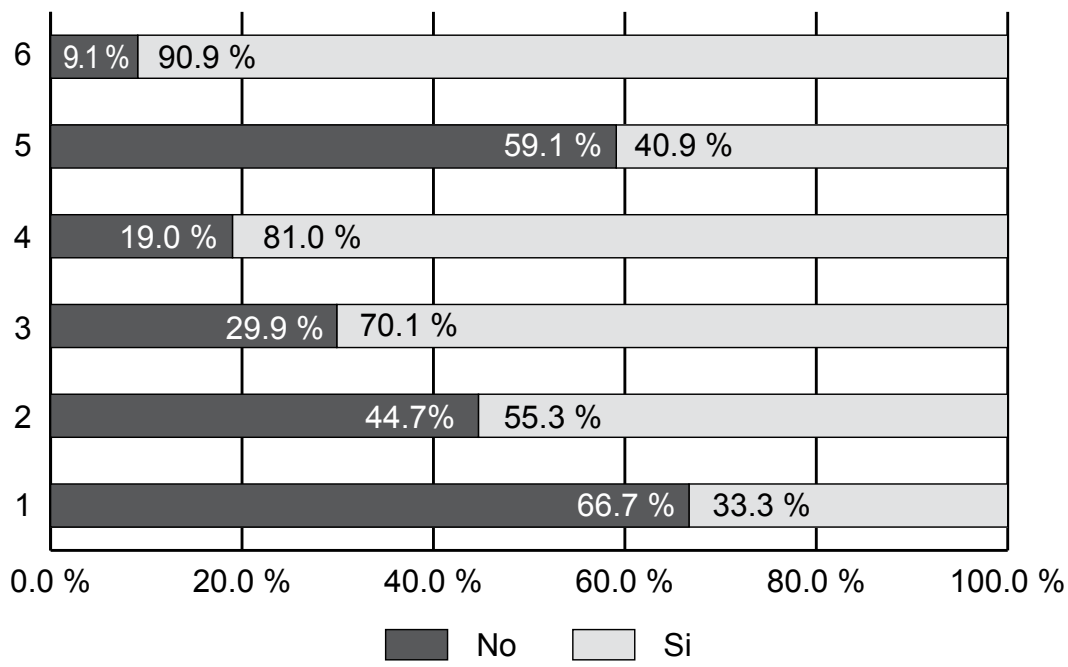

Fuente: cálculos de los autores con base en la encuesta aplicada. 
Se buscó identificar la posible existencia de una relación entre el estrato y el porcentaje de encuestados que ve los debates políticos. En general, se observa que, a mayor estrato, el porcentaje de encuestados que ve los debates políticos en época electoral es mayor, excepto en el estrato 5. Los porcentajes de encuestados del estrato 1 que ve los debates políticos en época electoral es el 33.3\%, del estrato 2 el $55.3 \%$, del estrato 3 el $70.1 \%$, del estrato 4 el $81 \%$, del estrato 5 el $40.9 \%$ y del estrato 6 el $90.9 \%$. Por lo tanto, se puede concluir entonces que los estratos 2, 3,4 y 6 tienen un comportamiento similar, pues la mayoría de las personas de estos estratos ve los debates políticos. El estrato 1 y el estrato 5 por el contrario, en su mayoría, no ven estos debates en épocas electorales.

Gráfico 16. Diferenciación entre el sexo del encuestado y la conducta de buscar información adicional a la que reciben en medios como radio y televisión

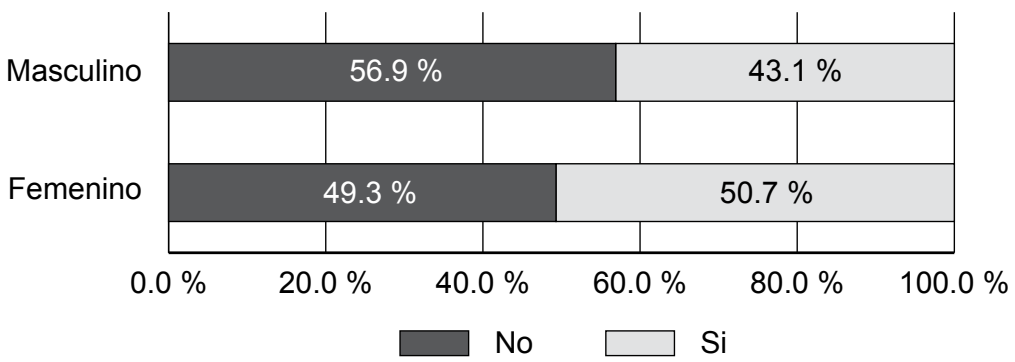

Fuente: cálculos de los autores con base en la encuesta aplicada.

Al preguntar si el encuestado buscaba información adicional a la que recibe en medios como radio y televisión en épocas electorales, se observa que las mujeres en su mayoría buscan información adicional a la que reciben en medios como la radio y la televisión en épocas electorales (50.7\%), mientras que solo el $43.1 \%$ de los hombres encuestados busca información adicional.

Gráfico 16. Diferenciación entre el rango de edad y su confianza en los periódicos

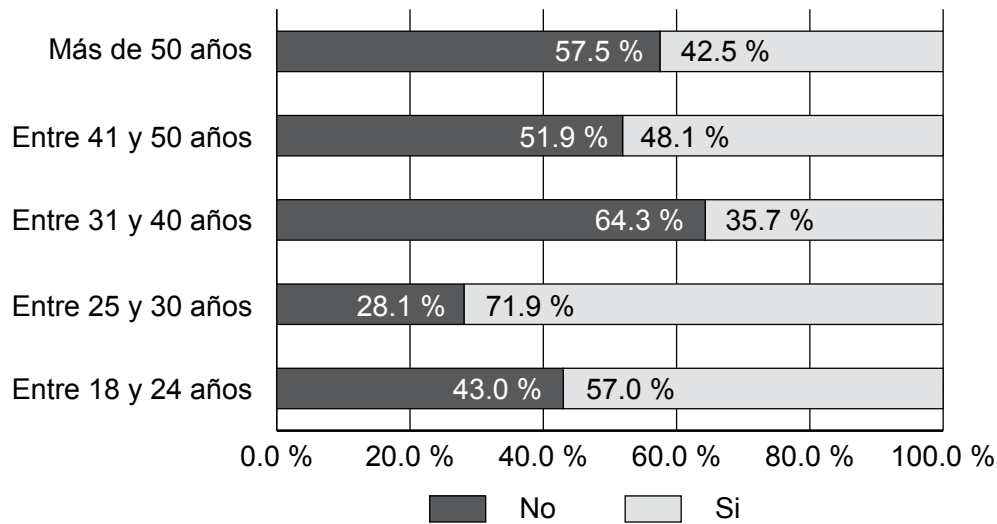

Fuente: cálculos de los autores con base en la encuesta aplicada. 
ó un cruce de variables entre si la gente piensa que el periódico es confiable o no según su edad, y se encontró que quienes piensan que los periódicos son confiables son los adultos jóvenes. Después de los 30 años las personas desconfían de este medio de comunicación.

\section{Conclusiones}

Teniendo en cuenta que este estudio buscó identificar algunas percepciones de los electores frente al marketing político, así como conocer algunas conductas o acciones de estos en la etapa preelectoral respecto de la comunicación política, las conclusiones que se muestran a continuación recogen los resultados más relevantes o significativos del estudio y se presentan diferenciando los resultados relacionados con percepciones y los relacionados con conductas o comportamientos de los electores en época preelectoral. También se presentan algunos hallazgos relacionados con el ejercicio de contrastar algunas variables relevantes de la investigación con algunas características de los encuestados (con el análisis de tablas de contingencia).

Algunos hallazgos sobre percepciones son: aunque el 66\% de los encuestados considera que el mercadeo político es una herramienta útil para la democracia, el 92\% de los encuestados cree que existe manipulación a través de las campañas políticas; al comparar el grado de transparencia o engaño que perciben los encuestados entre programas de gobierno, propuestas políticas y debates políticos, se encontró que son estos últimos los que generan menos desconfianza, puesto que el $50.4 \%$ considera que los debates políticos son transparentes o parcialmente transparentes, mientras que solamente el $29.3 \%$ considera que los programas de gobierno son transparentes o parcialmente transparentes. Frente al concepto de mercadeo político como una técnica que permite captar y conocer las necesidades, deseos y aspiraciones de una sociedad para luego ganar el poder y solucionar dichas necesidades, solo el 36\% considera que sí se aplica este concepto en Colombia, en tanto que el $64 \%$ cree que no se aplica. El $70 \%$ de los encuestados considera que en época electoral hay un alto grado de saturación de propaganda política. De las actividades de comunicación preferidas por los encuestados, el 64\% de los encuestados prefieren los debates por televisión. Las demás alternativas indagadas presentan porcentajes relativamente bajos (solo el $27.2 \%$ prefieren las conferencias en universidades, el $20.4 \%$ reuniones en los barrios, el 17.6\% comerciales en televisión, $15.1 \%$ cuñas de radio y solo el $14.2 \%$ prefiere discursos en eventos).

Algunos hallazgos sobre conductas o comportamientos son: la razón principal para elegir una propuesta política es el programa de gobierno (41.8\%), seguido de la ideología (30.7\%) y del candidato (16\%). La principal acción para informarse que dicen realizar los encuestados en época preelectoral es ver los debates políticos (70.1\% versus el $29.9 \%$ que no los ve), seguido de leer los programas de gobierno (el 63.3\% afirma realizar esta acción versus el 36.7\% que declara 
no leerlos), mientras que la tercera acción que dicen realizar para informarse en época electoral es buscar información adicional a la que aparece en los medios como radio y televisión con un 46.6\% (el 53.4\% dice no buscar información adicional a la que recibe por radio y televisión).

Algunos hallazgos del análisis de las tablas de contingencia son: se encontró una relación directa entre el estrato y el programa de gobierno como razón principal del voto, es decir, a mayor estrato, mayor porcentaje del programa de gobierno como razón principal del voto; el candidato como razón principal del voto decrece en la medida en que aumenta el estrato; en conjunto, la ideología y el programa de gobierno son razones que van creciendo en la medida en que sube el estrato, mientras que la tradición, el partido y el candidato son razones que decrecen a medida que aumenta el estrato. Sobre el grado de influencia de las acciones publicitarias en el voto según rangos de edad, se observa que, a mayor rango de edad del encuestado, este expresa que las acciones publicitarias tienen menor grado de influencia.

\section{Referencias}

Anduiza, E., y Agustí, B. (2004). Comportamiento político y electoral. Barcelona: Ariel.

Becccassino, A. (2003). El precio del poder. Cómo se vende la imagen de un político. Bogotá: Aguilar.

Blackwell, R., Miniard, P., y Engel, J. (2002). Comportamiento del consumidor (9a․ edición). México: Ediciones Paraninfo.

Canel, M. J. (2006). Comunicación política. Una guía para su estudio y práctica (2da edición). Madrid: Tecnos.

Cárdenas Ruiz, J. D. (2013). Caracterización del comportamiento electoral colombiano desde una perspectiva multidimensional. Ponencia presentada en el Congreso ALICE 2013. Toluca, México. Recuperado de http://www.alice-comunicacionpolitica.com/abrir-ponencia.php?f=433F5236c8954331379322005-ponencia-1.pdf

Cortés, R. (2009). La comunicación política como forma moderna de comunicación: del discurso retórico al discurso icónico. Una aproximación crítica. San Cristóbal: Universidad de Los Andes. Recuperado de hlttp://www.saber.ula.ve/bitstream/123456789/31534/7/introduccion.pdf

Crespo Martínez, I., y Moreno Martínez, C. (2015). Los efectos de la comunicación política en el comportamiento electoral. Revista Derecho Electoral (20), 76110. Recuperado de http://www.tse.go.cr/revista/art/20/crespo_moreno.pdf 
España, D., y Rivera, E. (2012). Los universitarios y la democracia en Bogotá: un caso de marketing político. Papel Político, 17(1), 15-55. Recuperado de http://www.scielo.org.co/pdf/papel/v17n1/v17n1a02.pdf

Guzmán, C., y Ramírez, A. (2015). El elector colombiano. Una aproximación al perfil del votante de los principales partidos en elecciones presidenciales, 2002-2010. Revista Investigación y Desarrollo, 23(1), 165-198. Recuperado de http://rcientificas.uninorte.edu.co/index.php/investigacion/article/ view/6448/6872

López García, G. (2001). Comunicación electoral y formación de la opinión pública. Las elecciones generales de 2000 en la prensa española (tesis doctoral). Departamento de Teoría de los lenguajes, Universidad de Valencia. Valencia. Recuperado de http://www.uv.es/=guilopez/documentos/tesiscompleta.pdf

Maarek, P. (2009). Marketing político y comunicación. Claves para una buena información política. Barcelona: Ediciones Paidós Ibérica, S. A.

Malamud, A. (2003). Los partidos políticos. En J. Pinto, Introducción a la ciencia política, pp. 321-350. Buenos Aires: Eudeba.

Misión de Observación Electoral (MOE) (2011). Encuesta: percepción electoral de los votantes colombianos. Bogotá: Torre Blanca Agencia Gráfica. Recuperado de http://moe.org.co/home/doc/encuesta/encuestamoe.pdf

Ochoa González, O. (2000). Comunicación política y opinión pública. México: McGrawHill.

Remes, A. D. (2001). Elección racional, cultura y estructura: tres enfoques para el análisis político. Revista Mexicana de Sociología, 63(1), 41-70. Recuperado de https://ctinobar.webs.ull.es/1docencia/SOCIOLOG\%C3\%8DA\%20 POL\%C3\%8DTICA/ENFOQUES.pdf

Reyes Montes, M.C., O'Quínn Parrales, J. A., Morales, Gómez, J. M., y Rodríguez Manzanares, E. (2011). Reflexiones sobre la comunicación política. Espacios Públicos, 14(30), 85-101. Recuperado de http://www.redalyc.org/ pdf/676/67618934007.pdf

Rodríguez-Raga, J., y Seligson, M. (2011). Cultura política de la democracia en Colombia, 2011. Actitudes democráticas en la sucesión. Bogotá: Universidad de los Andes y VanderbiltUniversity. Recuperado de http://www.vanderbilt. edu/lapop/colombia/2011-Colombia-Cultura-politica-de-la-democracia.pdf

Sibaja Quesada, G. (2012). Aula Virtual. ¿Cómo estudiar la comunicación política? Un zoom a sus elementos clave. Más poder Local (11). Recuperado de http://docplayer.es/2214769-Comunicacion-politica-y-estrategias-decampana.html 
Taylor, P.J., y Johnston, R.J. (1979). Geography of elections. Harmondsworth: Penguin Books.

Valdéz Zepeda, A., y Huerta Franco, D. A. (2011). ¿Qué mueve a los votantes? Un análisis de las razones y sinrazones del comportamiento político del elector. Revista Razón y Palabra (75). Recuperado de http://www.razonypalabra.org.mx/N/N75/varia_75/varia2parte/16_Valdez_V75.pdf

Vásquez, E. (2012). Seminario Comunicación Política. Ciencias de la Comunicación, III ciclo, Universidad Católica de Trujillo Benedicto XVI. Recuperado de https://edvasquez.files.wordpress.com/2012/05/areas-deestudio-cp-y-procesos-de-interaccion.pdf

Vitkovsky, O., y Kolossov, V. (1980). Regional político-geographical studies: Some theoretical and practical conclusions. International Political Science Review, 1(4). 